\title{
PENGEMBANGAN KIT PRAKTIKUM ELEKTRONIKA DASAR II BERBASIS SIMULATOR PROTEUS UNTUK MENINGKATKAN KEMAMPUAN MAHASISWA DALAM PEMECAHAN MASALAH
}

\author{
Suwardi , Erik Ayatullah, Haidul \\ Laboratorium Fisika, FMIPA, Universitas Bengkulu \\ Jalan WR. Supratman, Kandang Limun, Kota Bengkulu \\ Email*: suwardi@unib.ac.id
}

\begin{tabular}{c|c|c|c} 
Diterima 9 Maret 2021 & Direvisi 7 April 2021 & Disetujui 18 April 2021 & Dipublikasikan 29 April 2021 \\
\hline \multicolumn{4}{c}{ https://doi.org/10.33369/jkf.4.1.9-16 } \\
\hline
\end{tabular}

\begin{abstract}
ABSTRAK
Penelitian ini bertujuan untuk mengembangkan kit praktikum Elektronika Dasar II berbasis simulator Proteus untuk meningkatkan kemampuan pemecahan masalah mahasiswa.Hasil observasi dalam prapenelitian menunjukkan bahwa mahasiswa kesulitan merangkai komponen elektronika, kekurangan waktu praktikum, dan kesulitan dalam mendapatkan data.Untuk mengatasi permasalahan ini dilakukan pengembangan kit praktikum Elektronika Dasar IIberbasis menggunakan simulator Proteus. Melalui kit praktikum mahasiswa fokus pada proses pengambilan data dan menganalisis sinyal keluaran rangkaian elektronika.Sedangkan simulator Proteus dapat membantu dalam mengamati gejala-gejala yang tidak dapat diamati langsung dan sebagai data pembanding. Penelitian ini merupakan jenis penelitian dan pengembangan dengan tahapan adalah analisis kebutuhan, pengembangan produk awal, validasi ahli, uji lapangan dan revisi produk. Penelitian ini dilakukan di Laboratorium Fisika FMIPA Universitas Bengkulu semester ganjil 2018/2019dengan subyek penelitian ini adalah 22 mahasiswa. Pengumpulan data dilakukan menggunakan metode observasi dan kuesioner yang dianalisis secara deskriptif kuantitatif. Hasil penelitian menunjukkan bahwa kit praktikum yang berhasil dikembangkan terdiri dari delapan percobaan yaitu penguat common drain, common source, emitor ditanahkan, pushpull, respon frekuensi rendah, inverting dan non inverting, integrator dan diferensiator, dan filter aktif. Kelayakan kit praktikum sebagai media pembelajaran di laboratorium berdasarkan validasi ahli sebesar 82,50\% (sangat layak) dan berdasarkan pengguna sebesar $82,64 \%$ (sangat layak).
\end{abstract}

Kata kunci: kit praktikum elektronika dasar II, simulator proteus, praktikum berbasis masalah

\begin{abstract}
This study aims to develop a Basic Electronics II practicum kit based on the Proteus simulator to improve students' problem solving abilities. The results of observations in the pre-study showed that students had difficulty assembling electronic components, lack of practicum time, and difficulties in obtaining data. To overcome this problem, the development of Basic Electronics II based practicum kit using the Proteus simulator is carried out. Through the practicum kit students focus on the process of data retrieval and analyzing the electronic circuit output signal. Whereas the Proteus simulator can help in observing symptoms that cannot be observed directly and as comparative data. This research is a type of research and development with stages are needs analysis, initial product development, expert validation, field testing and product revision. This research was conducted in the Physics Laboratory of the University of Bengkulu FMIPA odd semester 2018/2019 with the subjects of this study were 22 students. Data collection was carried out using observation methods and questionnaires which were analyzed quantitatively descriptively. The results showed that the practicum kit that was successfully developed consisted of eight experiments namely common drain amplifier, common source, ground emitter, pushpull, low frequency response, inverting and non-inverting, integrators and differentiators, and active filters. The feasibility of the practicum kit as a learning media in a laboratory based on expert validation is $82.50 \%$ (very feasible) and based on the user is $82,64 \%$ (very feasible).
\end{abstract}

Keywords: basic electronics II practicum kit, proteus simulator, problem solving laboratory 


\section{PENDAHULUAN}

Elektronika Dasar II merupakan mata kuliah wajib di Program Studi Fisika FMIPA Universitas Bengkulu yang membahas dasar-dasar elektronika lebih lanjut. Dengan pengetahuan yang diperoleh dalam Elektronika Dasar II ini, mahasiswa diharapkan mampu memperbaiki peralatan elektronika, membuat peralatan berbasis elektronika, dan memodifikasi peralatan elektronika untuk meningkatkan kinerjanya. Hal ini sangat diperlukan mahasiswa dalam mengerjakan tugas akhir bidang minat instrumentasi (1). Pada Elektronika Dasar II terdapat 1 SKS praktikum yang selama ini praktikum Elektronika Dasar II menggunakan model praktikum ekspositori. Model praktikum ekspositori adalah model praktikum yang memfokuskan mahasiswa melakukan kegiatan merangkai komponen elektronika dan mengambil data mengikuti prosedur dalam SOP praktikum. Hasil observasi pada praktikum Elektronika Dasar II mahasiswa Program Studi Fisika kelas A dan kelas B semester ganjil 2017/2018 menunjukkan banyak permasalahan yang terdapat pada pelaksanaan praktikum. Permasalahan yang muncul adalah mahasiswa kesulitan merangkai komponen elektronika ke papan rangkaian, kekurangan waktu praktikum, dan mahasiswa kesulitan dalam mendapatkan data. Selama ini mahasiswa belum mampu mengatasi permasalahan yang timbul dalam praktikum secara mandiri.

Kondisi di atas menggambarkan kemampuan mahasiswa dalam menyelesaikan masalah yang dihadapinya saat praktikum masih rendah. Kesulitan pemecahan masalah disebabkan oleh mahasiswa kurang memahami materi dan kurang motivasi (2). Solusi yang ditawarkan untuk mengatasi permasalahan di atas adalah melalui pengembangan kit praktikum Elektronika Dasar II. Kit praktikum ini berisi rangkaian komponen elektronika yang sudah jadi dan siap digunakan. Mahasiswa fokus pada proses pengambilan data praktikum, menganalisis sinyal keluaran dari kit rangkaian, mempelajari karakteristik dari rangkaian penguat berdasarkan sinyal keluaran tersebut. Untuk membantu mahasiswa dalam mempelajari perilaku rangkaian yang disebabkan oleh perubahan nilai komponen elektronika, mahasiswa dapat melakukan simulasi menggunakan simulator proteus. Simulasi ini dapat dilakukan secara fleksibel tanpa terbatas ruang dan waktu, dapat dilakukan oleh mahasiswa secara berulang-ulang tanpa rasa takut akan resiko bahaya yang ditimbulkannya, dan membantu dalam mengamati gejala-gejala yang tidak dapat diobservasi secara langsung melalui praktikum di laboratorium (3). Sedangkan solusi yang ditawarkan untuk meningkatkan kemampuan mahasiswa dalam menyelesaikan masalah dengan menerapkan model praktikum berbasis masalah.

Model praktikum berbasis masalah dirancang untuk melatih mahasiswa dalam menerapkan berbagai strategi dalam memecahkan masalah. Model ini juga berpotensi mampu melatihkan keterampilan berpikir tingkat tinggi lainnya bila dikembangkan secara tepat sesuai kebutuhan (3). Model praktikum berbasis masalah dapat menjadikan mahasiswa lebih aktif, melatih mahasiswa untuk memecahkan masalah, mengemukakan hipotesis, menguji hipotesis, dan mengambil suatu kesimpulan berdasarkan data yang diperoleh (4). Masalah yang diberikan dalam praktikum menuntut mahasiswa untuk terampil dalam melakukan pengamatan dan pengukuran dalam praktikum. Berbagai keterampilan yang diasah dalam model tersebut berkaitan dengan indikator dari keterampilan proses sains (5). Model praktikum berbasis masalah merupakan elaborasi dari model pembelajaran berbasis masalah, komponen yang membedakannya hanyalah teknik penyelesaian masalah tersebut yang dilakukan melalui praktikum. Model pembelajaran berbasis masalah adalah suatu cara mengajar dengan menghadapkan mahasiswa kepada suatu permasalahan agar dipecahkan atau diselesaikan. Metode ini menuntut kemampuan untuk melihat sebab akibat, mengobservasi masalah, mencari hubungan antara berbagai data yang terkumpul kemudian menarik kesimpulan yang merupakan hasil pemecahan masalah (6).

Beberapa penelitian telah berhasil menerapkan model pembelajaran berbasis masalah dan terbukti meningkatkan kemampuan mahasiswa dalam pemecahan masalah adalah: pertama, penelitian Purwanto dan Koto yang menerapkan model pembelajaran berbasis masalah pada pembelajaran fluida statis di SMAN 2 Kota Bengkulu (7). Kedua, penelitian Putri, Risdianto dan Hamdani yang menerapkan model pembelajaran berbasis masalah pada mahasiswa pendidikan fisika FKIP Universitas Bengkulu (8). Ketiga, penelitian Agustina dan Connie melakukan 
penerapan model pembelajaran berbasis masalah untuk meningkatkan kemampuan pemahaman konsep matematis pada mahasiswa pendidikan matematika IAIN Bengkulu (9).

Berdasarkan hal di atas, peneliti merumuskan permasalahan dalam penelitian ini adalah bagaimana mengembangkan kit praktikum Elektronika Dasar II berbasis simulator Proteus yang dapat meningkatkan kemampuan pemecahan masalah mahasiswa. Penelitian ini bertujuan untuk mengembangkan kit praktikum Elektronika Dasar II berbasis simulator Proteus untuk meningkatkan kemampuan pemecahan masalah mahasiswa. Sedangkan manfaat penelitian ini adalah mengatasi ketiadaan kit praktikum Elektronika Dasar II, mengefektifkan waktu praktikum, dan meningkatkan kualitas praktikum. Luaran penelitian ini adalah berupa satu publikasi ilmiah pada jurnal nasional dan kit praktikum Elektronika Dasar II.

\section{METODE PENELITIAN}

Penelitian ini merupakan jenis penelitian dan pengembangan yaitu penelitian yang digunakan untuk menghasilkan produk tertentu dan menguji keefektifan produk tersebut (10). Dalam penelitian ini produk yang dikembangkan adalah kit praktikum Elektronika Dasar II. Uji kelayakan kit praktikum ini dilakukan melalui validasi oleh ahli materi, validasi oleh ahli media, dan uji coba penggunaan oleh mahasiswa. Penelitian ini dilakukan di Laboratorium Fisika FMIPA Universitas Bengkulu Juli - November 2018. Subyek penelitian ini adalah mahasiswa Program Studi Fisika FMIPA Universitas Bengkulu yang mengambil praktikum Elektronika Dasar II semester ganjil 2018/2019.

Prosedur penelitian ini mengikuti prosedur penelitian dan pengembangan modifikasi dari model penelitian dan pengembangan Borg \& Gall yang dilakukan oleh Sugiyono yang meliputi: (1) Analisis kebutuhan produk yang akan dikembangkan, (2) Pengembangan produk awal, (3) Validasi ahli, (4) Uji coba lapangan, dan (5) Revisi produk (10).

Pengumpulan data dilakukan dengan menggunakan metode observasi dan kuesioner. Metode observasi dilakukan untuk mengamati kegiatan praktikum sebelum dan setelah menggunakan kit praktikum yang dikembangkan. Sedangkan kuesioner digunakan untuk menilai produk yang dikembangkan dan peningkatan kemampuan mahasiswa dalam menyelesaikan masalah. Analisis data penelitian ini menggunakan deskriptif kuantitatif. Deskriptif kuantitatif adalah statistik yang digunakan untuk menganalisis data dengan cara mendeskripsikan atau menggambarkan data yang terkumpul sebagaimana adanya (10). Data kuantitatif yang diperoleh menggunakan skala Likert dengan tingkatan bobot nilai yang digunakan sebagai skala pengukuran adalah 4, 3, 2, 1. Berdasarkan data yang dikumpulkan dari instrumen penelitian, selanjutnya dengan mengacu bobot yang dipilih atas tiap pernyataan, kemudian menghitung skor rata-rata hasil penilaian menggunakan rumus:

$$
\bar{X}=\frac{\sum X}{n}
$$

Dimana $\bar{X}=$ skor rata-rata, $\mathrm{n}=$ jumlah penilai, dan $\sum X=$ skor total masing-masing penilai. Sedangkan perhitungan prosentase kelayakan kit praktikum dihitung menggunakan rumus:

Prosentase kelayakan $(\%)=\frac{\text { skor yang diobservasi }}{\text { skor yang diharapkan }} \times 100 \%$

Prosentase ini selanjutnya dirubah dalam bentuk pernyataan yang menunjukkan kelayakan kit praktikum sebagai produk penelitian ini menggunakan skala pengukuran Rating Scale pada Tabel 1.

Tabel 1. Kategori kelayakan kit praktikum berdasarkan rating scale

\begin{tabular}{lcc}
\hline No & Skor $(\%)$ & Kategori kelayakan \\
\hline 1. & $0 \%-25 \%$ & Tidak layak \\
2. & $25 \%-50 \%$ & Kurang layak \\
3. & $50 \%-75 \%$ & Layak \\
4. & $75 \%-100 \%$ & Sangat layak \\
\hline
\end{tabular}




\section{HASIL DAN PEMBAHASAN}

\subsection{Analisis Kebutuhan}

Analisis kebutuhan telah dilakukan dengan melakukan observasi praktikum Elektronika Dasar II semester ganjil 2017/2018 dan mengevaluasi penuntun praktikumnya. Hasil observasi menunjukkan bahwa mahasiswa kesulitan merangkai komponen elektronika ke papan rangkaian, kekurangan waktu praktikum, dan mahasiswa kesulitan dalam mendapatkan data praktikum. Hasil observasi ini ditindaklanjuti dengan mengevaluasi penuntun praktikum yang telah digunakan selama ini. Dalam penuntun praktikum lama terdapat delapan percobaan yaitu penguat gandengan $\mathrm{RC}$, penguat audio, penguat pushpull, penguat umpan balik, penguat emitor ditanahkan, penguat daya, inverting-noninverting, dan diferensiator-integrator. Evaluasi rangkaian elektronika dalam penuntun praktikum dilakukan dengan mensimulasikan semua rangkaian menggunakan simulator Proteus. Hasil simulasi ini menunjukkan dari delapan percobaan yang berhasil disimulasikan hanya empat percobaan yaitu penguat pushpull, penguat emitor ditanahkan, inverting-non inverting, dan diferensiator-integrator. Sedangkan empat percobaan lainnya diganti dengan percobaan lain yaitu penguat common drain, penguat common source, penguat respon frekuensi rendah, dan rangkaian filter aktif. Simulasi dari rangkaian elektronika hasil analisis kebutuhan dalam penelitian ini salah satunya ditunjukkan pada Gambar 1.
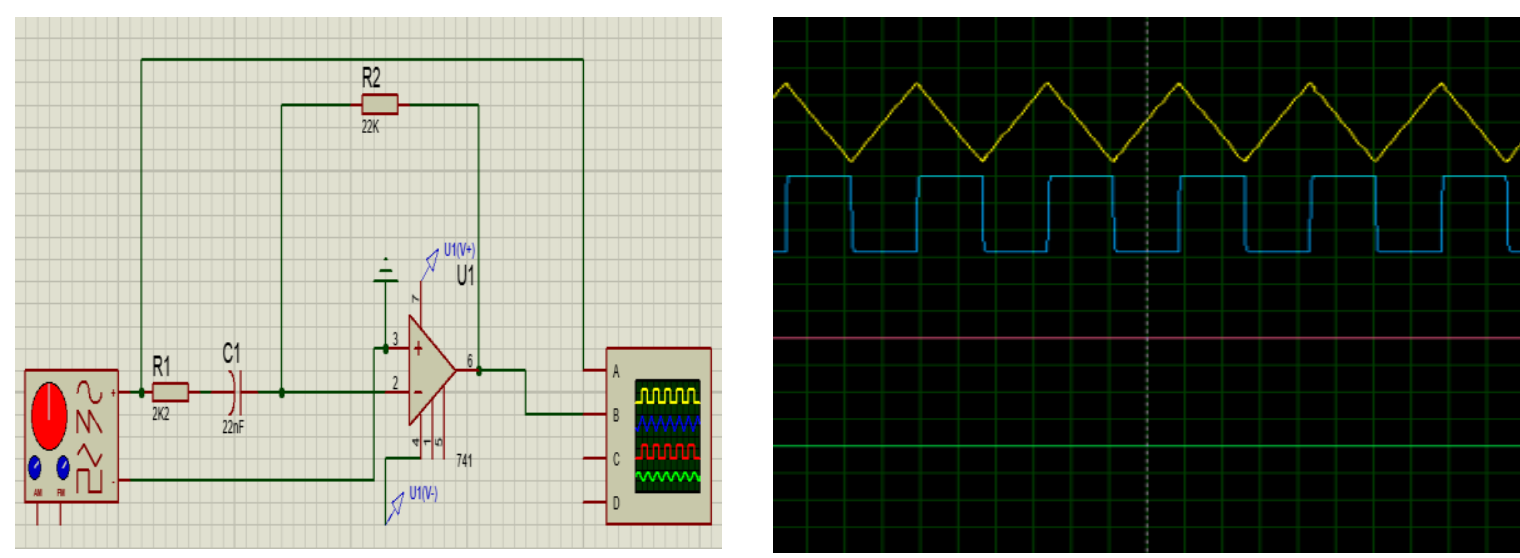

Gambar 1. Rangkaian diferensiator dan hasil simulasinya

\subsection{Pengembangan Produk Awal}

Berdasarkan hasil analisis kebutuhan di atas, selanjutnya dilakukan pengembangan produk awal yaitu membuat kit praktikum dari delapan materi percobaan yang telah ditetapkan sebelumnya. Pembuatan kit diawali dengan membuat desain gambar rangkaian elektronika kit praktikum yang akan dipindahkan ke PCB menggunakan perangkat lunak Proteus, salah satunya ditunjukkan pada Gambar 2.

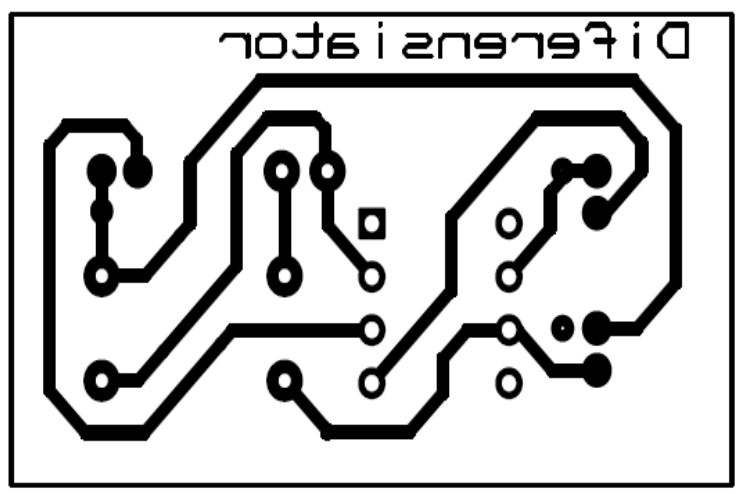

Gambar 2. Rangkaian diferensiator yang dipindahkan ke PCB 
Desain gambar rangkaian elektronika pada Gambar 2 selanjutnya dicetak pada kertas blue print film menggunakan printer laser. Hasil cetakan rangkaian pada blue print film ke PCB ini kemudian dipindahkan ke atas lapisan tembaga PCB dengan cara diseterika. Setelah dipastikan bahwa rangkaian pada blue print film menempel pada PCB secara sempurna, PCB direndam dalam larutan $\mathrm{FeCl}_{2}$ untuk menghilangkan lapisan tembaga PCB yang tidak digunakan. Tahap akhir pengembangan kit praktikum sebagai produk awal adalah proses pengeboran, pemasangan komponen elektronika di PCB, penyolderan, dan pengujian kit praktikum menggunakan catu daya, sinyal generator, dan osiloskop.

\subsection{Validasi Ahli}

Validasi ahli dilakukan oleh Dosen Jurusan Fisika FMIPA Universitas Bengkulu meliputi dua aspek, yaitu validasi kit praktikum ditinjau dari kelayakan media dan kelayakan materi. Kelayakan materi terdiri dari 7 pernyataan dan kelayakan materi terdiri dari 13 pernyataan. Hasil validasi ahli ditunjukkan pada Tabel 2.

Tabel 2. Hasil validasi ahli

\begin{tabular}{|c|c|c|c|c|}
\hline Aspek & No & Pernyataan & Skor & $\begin{array}{c}\text { Skor } \\
\text { Maksimal }\end{array}$ \\
\hline \multirow{7}{*}{$\begin{array}{l}\text { Kelayakan } \\
\text { Media }\end{array}$} & 1 & Pengaturan tata letak komponen pada PCB rapi & 4 & 4 \\
\hline & 2 & Jalur PCB pada kit praktikum sudah jelas & 4 & 4 \\
\hline & 3 & Penggunaan komponen dan ukuran komponen pada kit & 4 & 4 \\
\hline & 4 & $\begin{array}{l}\text { praktıkum sesual. } \\
\text { Desain kit praktikum menarik dan aman digunakan }\end{array}$ & 3 & 4 \\
\hline & 5 & $\begin{array}{l}\text { Kit praktikum mudah dibawa, mudah disimpan dan tidak } \\
\text { memakan tempat }\end{array}$ & 4 & 4 \\
\hline & 6 & Unjuk kerja kit praktikum secara keseluruhan baik & 3 & 4 \\
\hline & 7 & Kit praktikum mudah digunakan dalam praktikum & 3 & 4 \\
\hline \multirow{16}{*}{$\begin{array}{l}\text { Kelayakan } \\
\text { Materi }\end{array}$} & 8 & Kit praktikum sesuai dengan silabus & 3 & 4 \\
\hline & 9 & $\begin{array}{l}\text { Kit praktikum memenuhi kompetensi praktikum Elektronika } \\
\text { Dasar II }\end{array}$ & 3 & 4 \\
\hline & 10 & $\begin{array}{l}\text { Kit praktikum dapat digunakan sebagai alat praktikum untuk } \\
\text { mempelajari prinsip kerja penguat. }\end{array}$ & 3 & 4 \\
\hline & 11 & $\begin{array}{l}\text { Petunjuk praktikum menyajikan prosedur penggunaan kit } \\
\text { praktikum dengan baik }\end{array}$ & 2 & 4 \\
\hline & 12 & $\begin{array}{l}\text { Penggunaan simulator proteus dapat memandu mahasiswa } \\
\text { dalam mendapatkan sinyal keluaran yang benar }\end{array}$ & 4 & 4 \\
\hline & 13 & $\begin{array}{l}\text { Penggunaan simulator proteus memberikan keleluasaan } \\
\text { mahasiswa dalam mensimulasikan pengaruh nilai komponen } \\
\text { elektronika terhadap sinyal keluaran rangkaian penguat }\end{array}$ & 4 & 4 \\
\hline & 14 & $\begin{array}{l}\text { Penggunaan kit praktikum membantu dosen dalam } \\
\text { membimbing praktikum }\end{array}$ & 3 & 4 \\
\hline & 15 & $\begin{array}{l}\text { Kit praktikum memudahkan mahasiswa dalam melaksanakan } \\
\text { praktikum Elektronika Dasar II }\end{array}$ & 3 & 4 \\
\hline & 16 & $\begin{array}{l}\text { Penggunaan kit praktikum dan simulator proteus memudahkan } \\
\text { mahasiswa dalam mempelajari rangkaian penguat }\end{array}$ & 3 & 4 \\
\hline & 17 & $\begin{array}{l}\text { Penggunaan kit praktikum meningkatkan perhatian mahasiswa } \\
\text { pada materi praktikum }\end{array}$ & 3 & 4 \\
\hline & 18 & $\begin{array}{l}\text { Penggunaan kit praktikum yang dilengkapi dengan simulator } \\
\text { proteus meningkatkan kemampuan mahasiswa dalam } \\
\text { memecahkan masalah yang muncul dalam praktikum. }\end{array}$ & 3 & 4 \\
\hline & 19 & $\begin{array}{l}\text { Penggunaan kit praktikum meningkatkan motivasi mahasiswa } \\
\text { dalam praktikum }\end{array}$ & 3 & 4 \\
\hline & 20 & $\begin{array}{l}\text { Penggunaan kit praktikum mempermudah mahasiswa } \\
\text { menyelesaikan praktikum tepat waktu }\end{array}$ & 4 & 4 \\
\hline & \multicolumn{2}{|r|}{ JUMLAH } & 66,00 & 80,00 \\
\hline & \multirow{2}{*}{\multicolumn{2}{|c|}{$\begin{array}{l}\text { RATA-RATA } \\
\text { KELAYAKAN }\end{array}$}} & 3,30 & 4,00 \\
\hline & & & \multicolumn{2}{|c|}{$82,50 \%$} \\
\hline
\end{tabular}


Berdasarkan Tabel 2 dapat diketahui bahwa kelayakan kit praktikum yang dikembangkan dalam penelitian ini menurut ahli media dan materi sebesar 82,50\% (sangat layak). Dari sisi kelayakan media, kit praktikum yang dihasilkan dalam penelitian ini rapi, jalurnya jelas, desainnya menarik, mudah dibawa, tidak memakan tempat, mudah disimpan, dan aman digunakan. Hal ini sesuai dengan hasil penelitian Zidny yang menyatakan bahwa alat peraga praktikum dikatakan layak ketika memenuhi persyaratan, diantaranya efisien digunakan (kemudahan alat untuk dipindah-pindah dan dirangkai sehingga menghemat waktu praktik) dan aman bagi mahasiswa (11). Sedangkan dari sisi kelayakan materi, kit praktikum ini sesuai dengan silabus, berfungsi dengan baik, dan memudahkan mahasiswa dalam praktikum sehingga memperoleh data tepat waktu. Masukan dari ahli terkait dengan produk penelitian ini adalah agar dilengkapi dengan penuntun praktikum berbasis masalah sesuai rencana untuk menerapkan model praktikum berbasis masalah, jumlah kit untuk masing-masing percobaan diperbanyak proporsional dengan jumlah mahasiswa, dan memperkaya materi praktikum.

\subsection{Uji Lapangan}

Kit praktikum yang telah mendapat validasi ahli diuji cobakan kepada mahasiswa sebagai pengguna kit praktikum tersebut. Uji coba terbatas ini bertujuan untuk melihat tanggapan mahasiswa terhadap penggunaan kit praktikum dalam praktikum Elektronika Dasar II. Uji lapangan dilakukan pada mahasiswa fisika yang melakukan praktikum Elektronika Dasar II semester ganjil 2018/2019 di kelas Fisika B dengan melibatkan 22 mahasiswa. Mahasiswa praktikum menggunakan kit praktikum produk penelitian ini dan setelah selesai praktikum diminta untuk mengisi kuesioner yang telah disiapkan. Hasil kuesioner yang merupakan tanggapan pengguna kit praktikum ditunjukkan pada Tabel 3.

Tabel 3. Hasil uji lapangan kit praktikum oleh mahasiswa

\begin{tabular}{|c|c|c|c|}
\hline Pernyataan & $\begin{array}{l}\text { Skor rata- } \\
\text { rata }\end{array}$ & $\begin{array}{c}\text { Skor } \\
\text { Maksimal }\end{array}$ & $\begin{array}{l}\text { Kelayakan } \\
(\%)\end{array}$ \\
\hline $\begin{array}{l}\text { Saya lebih bersemangat melaksanakan praktikum dengan } \\
\text { menggunakan kit praktikum yang dilengkapi dengan simulator } \\
\text { proteus }\end{array}$ & 3,59 & 4 & 89,77 \\
\hline $\begin{array}{l}\text { Saya mendapatkan keterampilan baru dalam praktikum dengan } \\
\text { menggunakan kit praktikum yang dilengkapi simulator proteus }\end{array}$ & 3,41 & 4 & 85,23 \\
\hline $\begin{array}{l}\text { Penggunaan kit praktikum memudahkan saya dalam praktikum } \\
\text { Elektronika Dasar II. }\end{array}$ & 3,64 & 4 & 90,91 \\
\hline $\begin{array}{l}\text { Saya merasa praktikum menggunakan kit praktikum dan } \\
\text { simulator proteus lebih praktis dibandingkan praktikum dengan } \\
\text { merangkai komponen dalam breadboard }\end{array}$ & 3,64 & 4 & 90,91 \\
\hline Saya dapat menggunakan kit praktikum dengan baik & 2,86 & 4 & 71,59 \\
\hline $\begin{array}{l}\text { Pengaturan tata letak komponen elektronika pada kit praktikum } \\
\text { sudah rapi }\end{array}$ & 3,09 & 4 & 77,27 \\
\hline $\begin{array}{l}\text { Penggunaan simulator proteus memandu saya dalam } \\
\text { mendapatkan data percobaan dengan benar }\end{array}$ & 3,73 & 4 & 93,18 \\
\hline Kit praktikum aman digunakan dalam praktikum & 3,50 & 4 & 87,50 \\
\hline Kit praktikum dapat berfungsi dengan baik & 2,86 & 4 & 71,59 \\
\hline $\begin{array}{l}\text { Penggunaan kit praktikum membantu saya dalam } \\
\text { menyelesaikan praktikum tepat waktu }\end{array}$ & 3,14 & 4 & 78,41 \\
\hline $\begin{array}{l}\text { Penggunaan kit praktikum yang dilengkapi simulator proteus } \\
\text { meningkatkan kemampuan saya dalam memecahkan masalah } \\
\text { yang timbul dalam praktikum }\end{array}$ & 2,91 & 4 & 72,73 \\
\hline JUMLAH & 36,00 & 44,00 & 909,09 \\
\hline RATA-RATA & 3,31 & 4,00 & 82,64 \\
\hline
\end{tabular}

Secara keseluruhan skor kelayakan kit praktikum dari uji pemakaian oleh 22 mahasiswa memperoleh presentase sebesar $82,64 \%$ sehingga masuk pada kategori sangat layak. Mahasiswa merasakan mudah dalam menggunakan kit praktikum, lebih praktis, mampu menyelesaikan 
pengambilan data tepat waktu, dan mampu menyelesaikan masalah yang timbul dalam proses pengambilan data. Hasil ini menunjukkan bahwa kit praktikum yang dilengkapi dengan simulator Proteus dapat memudahkan mahasiswa dalam praktikum, menyelesaikan praktikum tepat waktu, dan dapat membantu mahasiswa dalam melakukan berbagai perlakuan dalam praktikum dengan bantuan simulator proteus.

\subsection{Revisi Produk}

Berdasarkan hasil validasi ahli dan uji lapangan terbatas diketahui bahwa produk penelitian ini belum dilengkapi dengan penuntun praktikum dan jumlah kit untuk masing-masing percobaan perlu diperbanyak sesuai dengan jumlah mahasiswa. Maka sebelum digunakan dalam skala yang lebih luas, kit ini harus dilengkapi dengan penuntun praktikum agar mahasiswa dapat melakukan percobaan dengan mudah dan hasil percobaannya konsisten. Hal ini sesuai dengan penelitian Zidny, Yusrina, Aryoningtyas, Elvina, Halimah, Ayuni, \& Hadiyati yang menyatakan bahwa efisiensi alat dan keterulangan merupakan aspek penting kelayakan kit praktikum agar mudah digunakan dan hasilnya konsisten (11). Hal lain yang ditemukan saat pengujian kit adalah sinyal keluaran hasil simulasi dan sinyal keluaran dari kit praktikum tidak sama. Untuk memverifikasi hal ini telah dilakukan pengujian ulang terhadap kit praktikum lebih teliti. Hasil pengujian ulang menunjukkan bahwa sinyal keluaran kit praktikum memang tidak halus seperti hasil simulasi namun memiliki pola dan karakteristik yang sama. Hal ini diduga karena pengaruh penyolderan komponen yang kurang sempurna sehingga masih muncul noise. Selain hal diatas, revisi produk juga dilakukan dengan menata ulang perkabelan kit agar lebih rapi dan memperbanyak jumlah kit praktikum. Hasil proses ini merupakan produk penelitian berupa kit praktikum Elektronika Dasar II yang salah satunya ditunjukkan pada Gambar 3.

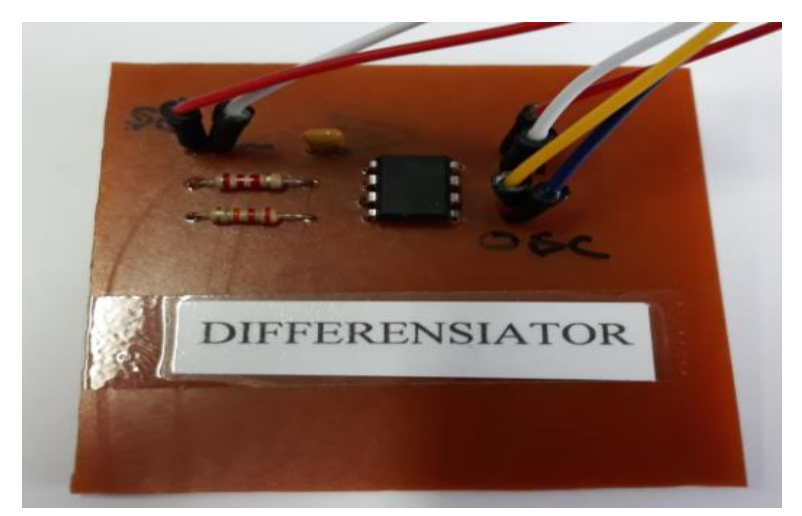

Gambar 3. Kit Praktikum Elektronika Dasar II (Penguat diferensiator)

\section{SIMPULAN DAN SARAN}

Telah berhasil dikembangkan kit praktikum Elektronika Dasar II yang terdiri dari delapan percobaan yaitu penguat common drain, penguat common source, penguat emitor ditanahkan, penguat pushpull, penguat respon frekuensi rendah, inverting dan non inverting, integrator dan diferensiator, dan rangkaian filter aktif. Kelayakan kit praktikum ini sebagai peralatan praktikum berdasarkan validasi ahli sebesar $82,50 \%$ (sangat layak) dan berdasarkan validasi pengguna sebesar $82,64 \%$ (sangat layak). Perlu penelitian lanjutan untuk melengkapi kit praktikum dengan penuntun praktikum berbasis penyelesaian masalah dan instrumen penilaian berbasis kinerja agar model praktikum berbasis masalah dapat diterapkan dengan baik.

\section{UCAPAN TERIMA KASIH}

Penulis mengucapkan terimakasih kepada Pimpinan Fakultas MIPA Universitas Bengkulu yang telah mendanai penellitian ini melalui Skema Penelitian Pembinaan FMIPA Universitas Bengkulu tahun 2018. 


\section{DAFTAR PUSTAKA}

1. Suwardi. Pengembangan instrumen penilaian kinerja untuk mengevaluasi keterampilan proses mahasiswa dalam praktikum Elektronika Dasar I. J Pendidik Bumi Rafflesia. 2014;(1):119 - 134.

2. Azizah R, Yuliati L, Latifah E. Kesulitan pemecahan masalah fisika pada siswa SMA. J Penelit Fis dan Apl. 2015;5(2):44-50.

3. Sutarno S, Setiawan A, Suhandi A, Kaniawati I, Putri DH. Keterampilan Pemecahan Masalah Mahasiswa Dalam Pembelajaran Bandul Fisis Menggunakan Model Problem Solving Virtual Laboratory. J Pendidik Fis dan Teknol. 2017;3(2):164.

4. Farid M, Leny. Pengaruh model pembelajaran problem solving berbantuan multimedia interaktif terhadap keterampilan generik sains dan hasil belajar siswa pada materi hidrolisis garam. J Inov Pendidik Sains. 2016;7(1):10-8.

5. Malik A, Handayani W, Nuraini R. Model praktikum problem solving laboratory untuk meningkatkan keterampilan proses sains mahasiswa. In: . 2015, Bandung. In: Prosiding Simposium Nasional Inovasi dan Pembelajaran Sains. Bandung; 2015.

6. Ellianawati, Subali B. Penerapan model problem solving laboratory sebagai upaya untuk memperbaikikualitas praktikum fisika dasar. J Pendidik Fis Indones. 2010;(6):90-7.

7. Purwanto A, Koto I. Upaya peningkatan kemempuan pemecahan masalah siswa kelas XI IPA SMAN 2 Kota Bengkulu dengan penerapan model problem based learning. J Pendidik Eksakta. 2017;1(2):68 - 72.

8. Putri DH, Risdianto E, Hamdani D. Upaya meningkatkan kemampuan pemecahan masalah melalui model pembelajaran problem based learning berbantuan virtual problem sheet. $\mathbf{J}$ Pendidik Eksakta. 2017;1(2):73 - 77.

9. Agustina J, Connie. Penerapan model pembelajaran based problem untuk meningkatkan kemampuan pemahaman konsep matematis mahasiswa tadris matematika IAIN Bengkulu. $\mathbf{J}$ Pendidik Eksakta. 2017;1(2):78 - 83.

10. Sugiyono. Metode Penelitian Pendidikan: Pendekatan Kuantitatif, Kualitatif, dan R \& D. Bandung: Alfabeta; 2006.

11. Zidny R, Yusrina D, Aryoningtyas I, Elvina NI, Halimah M, Ayuni ND, et al. Uji kelayakan kit praktikum pengujian kepolaran senyawa dari material sederhana. J Ris Pendidik Kim. 2017;7(1):52-8. 